\title{
MHC class I-related chain B gene polymorphism is associated with virological response to pegylated interferon plus ribavirin therapy in patients with chronic hepatitis $\mathbf{C}$ infection
}

\author{
AYUMI ASADA ${ }^{1}$, MAKOTO SHIOYA ${ }^{1}$, RIE OSAKI ${ }^{1}$, TAKASHI NISHIMURA $^{1}$, TAKAYUKI TAKEUCHI ${ }^{2}$, \\ YOSHIAKI OKUMURA $^{3}$ and AKIRA ANDOH ${ }^{1}$ \\ ${ }^{1}$ Department of Medicine, Shiga University of Medical Science, Seta Tsukinowa, Otsu 520-2192; \\ ${ }^{2}$ Department of Medicine, Notogawa Hospital, Higashioumi 521-1223; ${ }^{3}$ Department of Medicine, \\ Shiga Hospital of Regional Health Care Promotion Organization, Fujimidai, Otsu 520-0846, Japan
}

Received November 14, 2014; Accepted December 12, 2014

DOI: $10.3892 /$ br.2014.406

\begin{abstract}
The outcome of antiviral therapy is associated with viral and host factors. In the present study, the association between MHC class I-related chain B $(M I C B)$ genotypes and therapeutic response to pegylated interferon plus ribavirin (PEG-IFN/RBV) therapy was investigated in hepatitis $\mathrm{C}$ virus (HCV)-infected patients. In total, 107 patients with chronic HCV infection (74 with HCV serotype 1 and 33 with serotype 2) were enrolled. Genotyping of $M I C B$ single-nucleotide polymorphism (SNP) rs3828913 and interleukin-28B (IL28B) SNP rs8099917 was performed using TaqMan ${ }^{\circledR}$ SNP genotyping assays. The genotype distribution of the $M I C B$ alleles was: CC, 79.4\%; CA, 17.8\%; and AA, 2.8\%. Sustained virological response (SVR) was achieved by $55.1 \%(59 / 107)$ of the HCV patients. The SVR rate of patients with $M I C B$ major (CC) alleles was $62.3 \%$ and this rate was significantly higher than that of the patients with $M I C B$ minor (CA and AA) alleles $(27.2 \%)(\mathrm{P}=0.0068)$. A multivariate logistic model showed that the $M I C B$ major genotype was an independent factor contributing to SVR (OR, 4.47; 95\% CI, 1.46-13.70; $\mathrm{P}=0.009)$. In addition, the $M I C B$ genotype was identified as the sole independent factor contributing to SVR and non-virological response in HCV serotype 1 patients with the $I L 28 B$ major genotype. In $\mathrm{HCV}$ serotype 2 patients, the $M I C B$ genotype was the sole significant factor contributing to SVR (OR, 30.68; 95\% CI, 2.72-346.3; $\mathrm{P}=0.006)$. In conclusion, the $M I C B$ genotype is a strong predictive factor for virological response to PEG-IFN/RBV therapy in $\mathrm{HCV}$ patients.
\end{abstract}

Correspondence to: Dr Makoto Shioya, Department of Medicine, Shiga University of Medical Science, Seta Tsukinowa, Otsu 520-2192, Japan

E-mail: makotani@belle.shiga-med.ac.jp

Key words: hepatitis C, interferon, MHC class I-related chain B, interleukin-28

\section{Introduction}

Hepatitis $\mathrm{C}$ virus (HCV) is the major cause of chronic liver diseases and $\sim 170$ million people are infected worldwide (1-4). Chronic HCV infection leads to life-threatening complications, such as liver cirrhosis (LC) and hepatocellular carcinoma (HCC) $(2,5-7)$. The current standard therapy for chronic $\mathrm{HCV}$ infection comprises of a combination of pegylated interferon- $\alpha$ (PEG-IFN- $\alpha)$ and ribavirin (RBV) $(1,8,9)$. Successful treatment, termed sustained virological response (SVR), is defined as undetectable HCV RNA 6 months after cessation of treatment (10-12). The SVR rate of PEG-IFN/RBV therapy has been reported as $40 \%$ in $\mathrm{HCV}$ serotype 1 patients and $75 \%$ in serotype 2 patients $(9,13,14)$. In addition, triple combination therapy, including $\mathrm{HCV}$ protease inhibitors, has recently been introduced. HCV protease inhibitors block the protease-dependent cleavage of the $\mathrm{HCV}$ polyprotein and inhibit an essential step of viral replication (15). Triple combination therapy achieves high antiviral responses $(15,16)$, but HCV protease inhibitors remain unavailable in numerous countries (17).

Innate immunity appears to play an important role in the pathogenesis of viral hepatitis $\mathrm{C}$ infection. Of the various subsets of cells involved in innate immunity, natural killer (NK) cells are enriched in the liver and provide inherent defense against a number of pathogens, including $\operatorname{HCV}(18,19)$. The prevalence and cytotoxicity of NK cells increase in the early stage of $\mathrm{HCV}$ infection, but they are downregulated in number and function in the chronic phase (19). Certain HCV peptides are inhibitory for NK cells, leading to the reduction of their antiviral activity (20).

NK cells exhibit various types of receptors, either inhibitory or activating, that can react with distinct ligands on infected cells. MHC class I-related chain B $(M I C B)$ is the ligand for the natural killer group 2 member D (NKG2D) activating receptor, which transduces positive intracellular signals in NK cells (21). In addition, dendritic cells (DCs) also express $M I C B$ upon IFN- $\alpha$ stimulation and gain the ability to activate $\mathrm{NK}$ cells. In patients with $\mathrm{HCV}$-infection, the $M I C B$ induction of DCs is severely impaired, suggesting that this impairment may play a role in $\mathrm{HCV}$ infection (22). 
Table I. Baseline characteristics of patients with HCV infection.

\begin{tabular}{lccc}
\hline Factors & Total & HCV serotype 1 & HCV serotype 2 \\
\hline Patients, $\mathrm{n}$ & 107 & 74 & 33 \\
Age, years & $58.2 \pm 9.9$ & $58.4 \pm 10.6$ & $57.6 \pm 8.6$ \\
Gender, male/female, $\mathrm{n}$ & $67 / 40$ & $46 / 28$ & $21 / 12$ \\
Body mass index, $\mathrm{kg} / \mathrm{m}^{2}$ & $23.4 \pm 4.0$ & $23.0 \pm 3.3$ & $24.3 \pm 5.2$ \\
HCV-RNA levels, $\log \mathrm{IU} / \mathrm{ml}$ & $6.25 \pm 0.73$ & $6.1 \pm 0.72$ & $6.1 \pm 0.86$ \\
AST, U/l & $60.0 \pm 42.2$ & $60.2 \pm 37.9$ & $59.2 \pm 50.7$ \\
ALT, U/l & $74.2 \pm 56.2$ & $73.1 \pm 44.8$ & $76.3 \pm 76.1$ \\
$\gamma$-GTP, U/l & $63.3 \pm 68.0$ & $62.8 \pm 54.1$ & $64.0 \pm 92.2$ \\
Hemoglobin, g/dl & $14.0 \pm 1.5$ & $14.1 \pm 1.5$ & $14.1 \pm 1.3$ \\
Platelets, $\mathrm{x} 10^{4} / \mathrm{mm}^{3}$ & $16.4 \pm 5.0$ & $15.8 \pm 4.4$ & $17.9 \pm 5.9$ \\
Total cholesterol, $\mathrm{mg} / \mathrm{dl}$ & $174.3 \pm 30.0$ & $173.4 \pm 28.6$ & $175.7 \pm 26.5$ \\
PEG-IFN, $\mu \mathrm{g} / \mathrm{kg}$ & $88.1 \pm 47.8$ & $104.5 \pm 43.6$ & $50.7 \pm 33.1$ \\
RBV, $\mathrm{mg} / \mathrm{kg} / \mathrm{day}$ & $10.1 \pm 2.4$ & $10.1 \pm 2.5$ & $10.1 \pm 2.1$ \\
Histological fibrosis stage: $1-2 / 3-4^{\mathrm{a}}, \mathrm{n}$ & $60 / 18$ & $39 / 14$ & $21 / 4$ \\
Histological inflammation grade: $0-1 / 2-3^{\mathrm{a}}, \mathrm{n}$ & $25 / 50$ & $13 / 38$ & $12 / 12$ \\
\hline
\end{tabular}

${ }^{a}$ Available sample number only. Data are presented as mean \pm standard deviation. HCV, hepatitis C virus; PEG-IFN, pegylated interferon; RBV, ribavirin.

The outcome of antiviral therapy has been reported to be associated with viral and host factors. Representative viral factors are the HCV genotype, high HCV RNA titers (23) and amino acid substitutions in the NS5A (24) and core region (25). Host factors include age, body mass index, insulin resistance and stage of liver fibrosis $(26,27)$. One host genetic factor, a single-nucleotide polymorphism (SNP) of the interleukin-28B (IL28B) gene, is strongly associated with the treatment outcome of IFN and RBV therapy (28-30). IL28B genotyping may lead to the development of personalized medicine, where it may aid to identify the candidates most likely to respond to antiviral treatment. $I L 28 B$ genotyping may be particularly important across ethnic divides as IL28B genotype differences may account for $>50 \%$ of ethnic bias (31). However, the $I L 28 B$ polymorphism does not explain all the treatment outcomes, and patients with the non-responder genotype may respond to therapy. Therefore, further studies aimed at finding new genetic factors for prediction of the therapeutic efficacy of antiviral therapy are required.

In the present study, the association between $M I C B$ genotypes and therapeutic response to PEG-IFN/RBV therapy was investigated in $\mathrm{HCV}$-infected patients. $M I C B$ genotypes are closely associated with therapeutic outcomes of PEG-IFN/RBV therapy and can be used as predictive factors of treatment outcome.

\section{Patients and methods}

Study populations. A total of 107 patients with chronic HCV infection (74 patients with HCV serotype 1 and 33 patients with serotype 2) that were treated with PEG-IFN/RBV therapy at the Hospital of Shiga University of Medical Science (Otsu, Japan), the Notogawa Hospital (Higashioumi, Japan) or the Shiga Hospital of Regional Health Care Promotion
Organization were enrolled in the study. Table I shows the baseline features of the patients. The patients received a weekly injection of PEG-IFN- $\alpha 2 b$ (Peg-Intron ${ }^{\circledR}$; MSD, Tokyo, Japan) at a dose of $1.5 \mu \mathrm{g} / \mathrm{kg}$ or PEG-IFN- $\alpha 2 \mathrm{a}$ (PEGASYS ${ }^{\oplus}$; Chugai Pharmaceutical, Tokyo, Japan) at a dose of 90 or $180 \mu \mathrm{g} / \mathrm{subject}$, and oral administration of RBV (Rebetol ${ }^{\circledR}$; MSD) for 24-72 weeks. The amount of RBV was adjusted based on the body weight of the patient $(600 \mathrm{mg}$ for $<60 \mathrm{~kg}$; $800 \mathrm{mg}$ for $60-80 \mathrm{~kg}$; or $1,000 \mathrm{mg}$ for $>80 \mathrm{~kg}$ ). Virological responses were defined as follows: SVR, undetectable $\mathrm{HCV}$ RNA at treatment week 24; non-virological response (NVR), continuous detection of HCV RNA throughout the observation period; and transient virological response (TVR), transient undetectable HCV RNA with its reappearance during the follow-up period. Adherence to $>80 \%$ of the scheduled doses during the first 12 weeks was required for inclusion in the study. Additionally, patients who discontinued treatment within 24 weeks of treatment for reasons other than virological failure were excluded.

Histological features, such as fibrosis and inflammation grade, were determined by pathologists at each hospital according to the Japanese chronic hepatitis classification (New Inuyama classification) (32). Written informed consent was obtained from all the patients. The ethics committee of each hospital approved the present study.

Serotyping of $H C V$. Serotyping was performed using an enzyme immunoassay kit (Imcheck F-HCV Gr; Kokusai-Shiyaku, Kobe, Japan).

Genotyping. Genomic DNA was extracted from peripheral leukocytes of whole blood samples using the QIAamp ${ }^{\circledR}$ DNA Blood mini kit (Qiagen, Hilden, Germany). The samples were genotyped for MICB rs3828913 and IL28B rs8099917 
Table II. Genotype distribution of MICB SNP rs3828913 and IL28B SNP rs8099917.

\begin{tabular}{|c|c|c|c|c|c|c|}
\hline \multirow[b]{2}{*}{ Variables } & \multicolumn{3}{|c|}{ MICB SNP rs 3828913} & \multicolumn{3}{|c|}{ IL28B SNP rs8099917 } \\
\hline & $\mathrm{CC}$ & CA & AA & $\mathrm{TT}$ & TG & GG \\
\hline HCV serotype $1, \mathrm{n}(\%)$ & $59(79.7)$ & 13 (17.6) & $2(2.7)$ & $57(77.0)$ & $16(21.6)$ & $1(1.4)$ \\
\hline HCV serotype $2, \mathrm{n}(\%)$ & $26(78.8)$ & $6(18.2)$ & $1(3.0)$ & $28(84.8)$ & $5(15.2)$ & $0(0.0)$ \\
\hline Total , n (\%) & 85 (79.4) & $19(17.8)$ & $3(2.8)$ & 85 (79.4) & 21 (19.6) & $1(0.9)$ \\
\hline НарМар, \% & 74.4 & 23.3 & 2.3 & 81.4 & 18.6 & 0.0 \\
\hline
\end{tabular}

$M I C B$, MHC class I-related chain B; IL28B, interleukin-28B; HCV, hepatitis C virus.

using the TaqMan ${ }^{\circledR}$ SNP Genotyping assay system (Applied Biosystems Inc., Foster City, CA, USA). Locus-specific polymerase chain reaction (PCR) primers and allele-specific $\mathrm{TaqMan}^{\circledR}$ probes were purchased from Applied Biosystems. For $M I C B$ genotyping, homozygosity for the major sequence $(\mathrm{CC})$ was defined as exhibiting the $M I C B$ major allele, whereas homozygosity (AA) or heterozygosity (CA) was defined as exhibiting the $M I C B$ minor allele. For the $I L-28$ genotypes, homozygosity for the major sequence (TT) was defined as exhibiting the IL28B major allele, whereas homozygosity (GG) or heterozygosity (TG) was defined as exhibiting the IL28B minor allele. HCV RNA levels were analyzed using the TaqMan reverse transcription PCR (RT-PCR) test (COBAS TaqMan ${ }^{\circledR}$ HCV test ver. 2.0; Roche, Branchburg, NJ, USA). The measurement ranges of these assays were 1.2-7.8 log IU.

Statistical analysis. Hardy-Weinberg equilibrium analysis was performed on these subjects by comparing the detected distribution of allele frequencies to the theoretical distribution estimated from the SNP allelic frequencies. $\mathrm{P}>0.05$ $\left(\chi^{2}\right.$ statistics) was considered to indicate an equilibrium. The categorical variables are presented as frequencies and percentages as required. The continuous variables are reported as the means \pm standard deviation (range). Statistically significant differences in treatment responses according to patient baseline parameters were determined by the Mann-Whitney U test for numerical variables and by Fisher's exact probability test or the $\chi^{2}$ test for categorical variables. Variables with a P-value of $<0.05$ in univariate analysis were included in stepwise multivariate logistic regression analysis. Variables with a P-value of $<0.05$ in multivariate analysis were considered to indicate a statistically significant difference. The odds ratio was also calculated. All the statistical analyses were carried out with Mac Toukei-Kaiseki Ver. 2 (Esumi Co., Ltd., Tokyo, Japan).

\section{Results}

MICB polymorphisms. The frequencies of the MICB genotypes in patients with HCV are shown in Table II. HapMap data are shown as a reference. The genotype frequency of the $M I C B$ alleles in $\mathrm{HCV}$ patients (CC, 79.4\%; CA, 17.8\%; and AA, 2.8\%) was almost identical to that determined from the HapMap data (CC, 74.4\%; CA, 23.3\%; and AA, 2.3\%). The frequency of the MICB rs $3828913 \mathrm{C}$ allele in $\mathrm{HCV}$ patients was $88.3 \%$.
Table III. Association between $M I C B$ genotypes and virological responses.

\begin{tabular}{lcccr}
\hline rs3828913 & SVR & NVR & TVR & n \\
\hline All HCV patients & & & & \\
CC, n (\%) & $53(62.3)$ & $13(15.2)$ & $19(22.4)$ & 85 \\
CA, n (\%) & $6(31.6)$ & $8(42.1)$ & $5(26.3)$ & 19 \\
AA, n (\%) & $0(0.0)$ & $0(0.0)$ & $3(100.0)$ & 3 \\
Total & $59(55.1)$ & $21(19.6)$ & $27(25.2)$ & 107 \\
HCV serotype 1 & & & & \\
patients & & & & \\
CC, n (\%) & $30(50.8)$ & $13(22.0)$ & $16(27.1)$ & 59 \\
CA, n (\%) & $4(30.8)$ & $8(61.5)$ & $1(7.6)$ & 13 \\
AA, n (\%) & $0(0.0)$ & $0(0.0)$ & $2(100.0)$ & 2 \\
Total & $34(45.9)$ & $21(28.4)$ & $19(25.6)$ & 74
\end{tabular}

HCV serotype 2

patients

$\begin{array}{lcllr}\text { CC, } \mathrm{n}(\%) & 23(88.4) & 0(0.0) & 3(11.5) & 26 \\ \text { CA, n (\%) } & 2(33.3) & 0(0.0) & 4(66.6) & 6 \\ \text { AA, n (\%) } & 0(0.0) & 0(0.0) & 1(100.0) & 1 \\ \text { Total } & 25(75.8) & 0(0.0) & 8(24.2) & 33\end{array}$

$M I C B$, MHC class I-related chain B; SVR, sustained virological response; NVR, non virological response; TVR, transient virological response.

The genotype frequencies of $I L 28 B$ polymorphisms were also analyzed. These data were consistent with a recent study of these polymorphisms in the Japanese population reported by Ochi et al (33).

Association between the MICB genotypes and treatment responses to $P E G-I F N / R B V$ therapy. Treatment responses to PEG-IFN/RBV therapy of patients with HCV are shown in Table III. SVR was achieved by 55.1\% (59/107) of the HCV patients. The SVR rate was significantly lower in HCV serotype 1 patients $(45.9 \%, 34 / 74)$ compared to serotype 2 patients $(75.8 \%, 25 / 33)(\mathrm{P}=0.008)$. NVR was noted in $19.6 \%(21 / 107)$ of the HCV patients. The NVR rate was significantly higher in serotype 1 patients $(28.4 \%, 21 / 74)$ compared to serotype 2 patients $(0.0 \%, 0 / 33)(\mathrm{P}=0.0002)$. TVR was noted in $25.2 \%$ (27/107) of the HCV patients. There was no significant 
Table IV. Univariate analysis of the factors associated with virological responses in all the HCV patients $(\mathrm{n}=107)$.

\begin{tabular}{lccccc}
\hline & & & & \multicolumn{2}{c}{ P-values } \\
\cline { 5 - 6 } Factors & SVR & NVR & TVR & SVR vs. non-SVR & NVR vs. non-NVR \\
\hline Patients, $\mathrm{n}$ & 59 & 21 & 27 & - & - \\
Age, years & $57.3 \pm 10.2$ & $57.7 \pm 11.1$ & $60.4 \pm 8.4$ & 0.26 & 0.54 \\
Gender, male/female, $\mathrm{n}$ & $37 / 22$ & $15 / 6$ & $15 / 12$ & 0.98 & 0.50 \\
Body mass index, kg/m & $23.4 \pm 3.7$ & $23.2 \pm 2.5$ & $23.8 \pm 5.4$ & 0.53 & 0.52 \\
HCV-RNA level, log IU/ml & $6.08 \pm 0.74$ & $6.36 \pm 0.69$ & $6.52 \pm 0.75$ & $0.0062^{\mathrm{b}}$ & 0.51 \\
AST, U/l & $63.4 \pm 49.3$ & $59.2 \pm 31.5$ & $52.8 \pm 31.2$ & 0.52 & 0.50 \\
ALT, U/l & $81.8 \pm 67.2$ & $66.8 \pm 39.3$ & $62.7 \pm 35.1$ & 0.40 & 0.52 \\
$\gamma$-GTP, U/l & $64.8 \pm 80.1$ & $79.8 \pm 62.8$ & $46.5 \pm 29.3$ & 0.36 & $0.039^{*}$ \\
Hemoglobin, g/dl & $14.1 \pm 1.5$ & $13.8 \pm 1.6$ & $14.1 \pm 1.1$ & 0.53 & 0.51 \\
Platelets, $\mathrm{x} 10^{4} / \mathrm{mm}{ }^{3}$ & $16.7 \pm 4.7$ & $16.6 \pm 5.3$ & $15.8 \pm 5.3$ & 0.51 & 0.53 \\
Total cholesterol, mg/dl & $172.8 \pm 30.9$ & $171.1 \pm 27.2$ & $179.4 \pm 30.3$ & 0.49 & 0.52 \\
PEG-IFN, $\mu$ g/kg & $82.3 \pm 48.8$ & $103.0 \pm 52.2$ & $89.5 \pm 40.6$ & 0.091 & 0.14 \\
RBV, mg/kg/day & $10.0 \pm 2.3$ & $10.4 \pm 2.8$ & $9.9 \pm 2.4$ & 0.53 & 0.44 \\
MICB genotype: major/minor, $\mathrm{n}$ & $53 / 6$ & $13 / 8$ & $19 / 8$ & $0.0068^{\mathrm{b}}$ & 0.055 \\
IL28B genotype: major/minor, $\mathrm{n}$ & $53 / 6$ & $11 / 10$ & $21 / 6$ & $0.0068^{\mathrm{b}}$ & $0.00062^{\mathrm{b}}$ \\
Fibrosis stage: $1-2 / 3-4^{\mathrm{a}}, \mathrm{n}$ & $35 / 9$ & $11 / 6$ & $14 / 3$ & 0.72 & 0.30 \\
Inflammation grade: 0-1/2-3 ${ }^{\mathrm{a}}, \mathrm{n}$ & $12 / 30$ & $5 / 11$ & $8 / 9$ & 0.32 & 0.92 \\
\hline
\end{tabular}

${ }^{\mathrm{a}}$ Available sample number only. ${ }^{\mathrm{b}} \mathrm{P}=0.004$. Data are presented as mean \pm standard deviation. $M I C B$, MHC class I-related chain $\mathrm{B} ; I L 28 B$, interleukin-28B; HCV, hepatitis C virus; SVR, sustained virological response; NVR, non virological response; TVR, transient virological response; AST, aspartate transaminase; ALT, alanine transaminase; GTP, glutamyl transpeptidase; PEG-IFN, pegylated interferon; RBV, ribavirin.
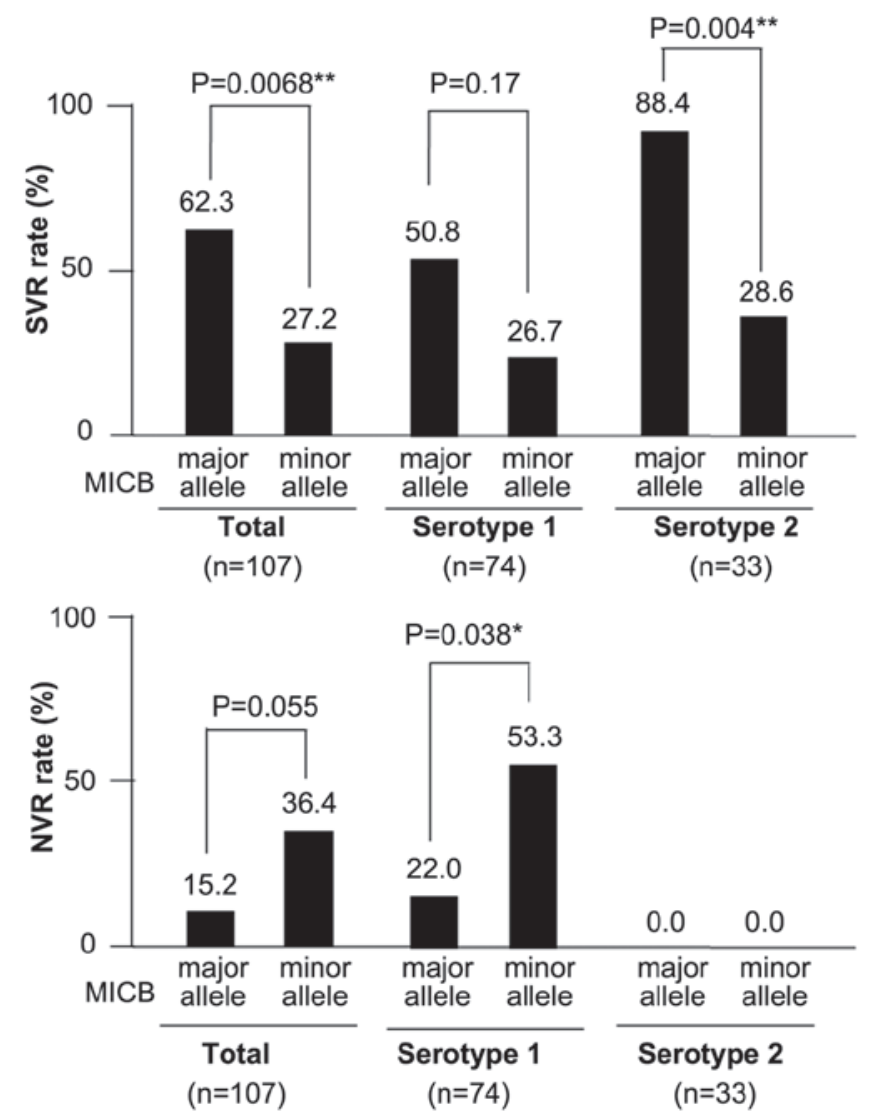

difference in the TVR rate between serotype $1(25.6 \%, 19 / 74)$ and $2(24.2 \%, 8 / 33)$ patients.

Association of the SVR rate with $M I C B$ genotypes of $\mathrm{HCV}$ patients was analyzed (Fig. 1). Of the total HCV patients, SVR was noted in $62.3 \%$ of patients with $M I C B$ major (CC) alleles and this rate was significantly higher than that of the patients with $M I C B$ minor (CA and AA) alleles (27.2\%). In HCV serotype 1 patients, the SVR rate (50.8\%) tended to be higher in patients with $M I C B$ major alleles compared to patients with $M I C B$ minor alleles (26.7\%), but this difference was not significant. In HCV serotype 2 patients, $88.4 \%$ of patients with $M I C B$ major alleles achieved SVR and this rate was significantly higher than that of the patients with $M I C B$ minor alleles $(28.6 \%)$.

By contrast, of the total HCV patients the NVR rate $(15.2 \%)$ tended to be lower in patients with $M I C B$ major alleles compared to the patients with $M I C B$ minor alleles (36.4\%). In particular, in HCV serotype 1 patients the NVR rate $(22.0 \%)$ was significantly lower in patients with $M I C B$ major alleles compared to patients with $M I C B$ minor alleles $(53.3 \%)$.

Factors contributing to virological responses in HCV patients. When pretreatment clinical data of all the $\mathrm{HCV}$ patients were analyzed and data of patients with SVR $(\mathrm{n}=59)$ and non-SVR (TVR plus NVR, $\mathrm{n}=48$ ) were compared, a significant difference was found in the distribution of serum HCV RNA levels

Figure 1. Association between the sustained virological response (SVR) rate (upper panel) and non-virological response (NVR) rate (lower panel) in hepatitis $\mathrm{C}$ virus (HCV) patients. ${ }^{*} \mathrm{P}<0.05$ and ${ }^{* * *} \mathrm{P}<0.01$. tified as significantly different between patients with NVR 
Table V. Multivariate analysis of the factors associated with SVR and NVR in the HCV patients $(n=107)$.

\begin{tabular}{lcll}
\hline Variables & OR & $95 \%$ CI & P-value \\
\hline Predicting SVR & & & \\
$\quad I L-28 B$ major genotype & 7.14 & $2.19-23.22$ & 0.001 \\
MICB major genotype & 4.47 & $1.46-13.70$ & 0.009 \\
Lower HCV-RNA & 2.39 & $1.19-4.78$ & 0.014 \\
Predicting NVR & & & \\
$\quad I L 28 B$ minor genotype & 5.63 & $1.94-16.38$ & 0.002 \\
Higher $\gamma$-GTP levels & 1 & $1.00-1.01$ & 0.121 \\
\hline
\end{tabular}

SVR, sustained virological response; NVR, non virological response; $\mathrm{OR}$, odds ratio; CI, confidence interval; IL28B, interleukin-28B; $M I C B$, MHC class I-related chain B; HCV, hepatitis C virus; GTP, glutamyl transpeptidase.

Table VI. Multivariate analysis of the factors associated with SVR and NVR in the HCV serotype 1 patients $(n=74)$.

\begin{tabular}{lrrl}
\hline Variables & OR & $95 \%$ CI & P-value \\
\hline Predicting SVR & & & \\
$\quad I L 28 B$ major genotype & 13.8 & $2.58-74.0$ & 0.002 \\
Lower HCV-RNA & 3.4 & $1.26-9.11$ & 0.016 \\
Predicting NVR & & & \\
IL28B minor genotype & 7.9 & $2.20-28.4$ & 0.002 \\
MICB minor genotype & 5.8 & $1.5-21.8$ & 0.01 \\
\hline
\end{tabular}

SVR, sustained virological response; NVR, non virological response; OR, odds ratio; CI, confidence interval; $I L 28 B$, interleukin-28B; $M I C B$, MHC class I-related chain B; $\mathrm{HCV}$, hepatitis $\mathrm{C}$ virus.

Table VII. Multivariate analysis of the factors associated with SVR and NVR in the IL28B major type of HCV serotype 1 patients $(n=57)$.

\begin{tabular}{lccc}
\hline Variables & OR & $95 \%$ CI & P-value \\
\hline $\begin{array}{l}\text { Predicting SVR } \\
\text { MICB major genotype }\end{array}$ & 6.74 & $1.19-38.2$ & 0.031 \\
$\quad$ Lower HCV-RNA & 2.77 & $0.88-8.72$ & 0.082 \\
Predicting NVR & & & \\
$\quad$ MICB minor genotype & 5.89 & $1.22-28.5$ & 0.027 \\
$\quad$ Lower hemoglobin levels & 0.6 & $0.34-1.06$ & 0.079 \\
\hline
\end{tabular}

SVR, sustained virological response; NVR, non virological response; OR, odds ratio; CI, confidence interval; IL28B, interleukin-28B; $M I C B, M H C$ class I-related chain $\mathrm{B}$; $\mathrm{HCV}$, hepatitis $\mathrm{C}$ virus.

(n=21) and non-NVR (SVR and TVR, $\mathrm{n}=86$ ) were $\gamma$-glutamyl transpeptidase (GTP) and the IL28B genotype.

A multivariate logistic model was applied for analysis of the three variables that were significantly different between patients with SVR and non-SVR to determine independent predictive factors (Table V). Among the 107 patients, the IL28B major (TT) genotype (OR, 7.14; 95\% CI, 2.19-23.22), lower HCV RNA levels (OR, 2.39; 95\% CI, 1.19-4.78) and the $M I C B$ major genotype (OR, 4.47; 95\% CI, 1.46-13.70) were identified as independent factors contributing to SVR. The IL28B minor genotype (TG and GG), but not $\gamma$-GTP levels, was identified as an independent factor contributing to NVR (OR, 5.63; 95\% CI, 1.94-16.38) (Table V).

Factors contributing to virological responses in HCV serotype 1 patients. In the 74 patients with HCV serotype 1, the IL28B major genotype and lower HCV-RNA level were identified as factors contributing to SVR. Multivariate logistic analysis showed that these were independent factors contributing to SVR (Table VI). Similar analytical processes identified that $M I C B$ and the $I L 28 B$ minor genotype are independent factors contributing to NVR (OR, 5.8; 95\% CI, 1.5-21.8 for MICB minor genotype; and OR, 7.9; 95\% CI, 2.2-28.4 for IL28B minor genotype) (Table VI).

HCV serotype 1 patients were divided into 57 patients with the $I L 28 B$ major (TT) genotype and 17 patients with the IL28B minor (TG and GG) genotype. When the study population was limited to HCV serotype 1 patients with the IL28B major genotype, the MICB genotype was identified as the sole independent factor contributing to SVR and NVR (Table VII).

Factors contributing to virological responses in HCV serotype 2 patients. In the 33 patients with HCV serotype 2, the $M I C B$ genotype was the sole significant factor contributing to SVR, whereas the IL28B genotype did not affect SVR (Table VIII). Using the IL28B, HCV-RNA and MICB genotypes as variables for simultaneous multivariate logistic regression analysis, the $\mathrm{OR}$ of $M I C B$ genotypes for prediction of SVR was 30.68 (95\% CI, 2.72-346.3; $\mathrm{P}=0.006)$.

\section{Discussion}

Combined PEG-IFN and RBV therapy has been the main treatment for patients with chronic hepatitis $\mathrm{C}$ in recent decades. However, the SVR rate is $\sim 40$ and $75 \%$ in patients with HCV serotype 1 and 2 infection, respectively $(1,13,14)$. In addition, PEG-IFN/RBV therapy is poorly tolerated due to the side-effects and requires long-term treatment (48 weeks). Therefore, pretreatment prediction of therapeutic response would be of great clinical benefit. In previous studies, host factors including genetic background (age, gender, ethnicity, platelets, liver fibrosis, obesity and IL28B polymorphisms) and viral factors (genotype, viral load and viral genetic polymorphisms) were reported to be associated with the outcome of PEG-IFN/RBV therapy $(1,34)$. In particular, a polymorphism upstream of the $I L 28 B$ gene is strongly associated with a favorable response in $\mathrm{HCV}$ serotype 1 patients $(6,28)$. However, the SVR rate of HCV serotype 1 patients possessing favorable $I L 28 B$ genotypes is as high as $50 \%$ (14), and thus, half of patients cannot achieve SVR (14). In addition, it remains unclear whether the $I L 28 B$ genotype aids in predicting virological response in HCV serotype 2 patients (35). For these reasons, identification of new 
Table VIII. Univariate analysis of the factors associated with SVR and TVR in HCV serotype 2 patients.

P-value

Factors

SVR

TVR

SVR vs. non-SVR

Patients, $\mathrm{n}$

Age, years

Gender, male/female, $\mathrm{n}$

Body mass index, $\mathrm{kg} / \mathrm{m}^{2}$

HCV-RNA level, log IU/ml

AST, U/l

ALT, U/1

$\gamma$-GTP, U/1

Hemoglobin, g/dl

Platelets, $\times 10^{4} / \mathrm{mm}^{3}$

Total cholesterol, mg/dl

PEG-IFN, $\mu \mathrm{g} / \mathrm{kg}$

$\mathrm{RBV}, \mathrm{mg} / \mathrm{kg} /$ day

$M I C B$ genotype: major/minor, $\mathrm{n}$

IL28B genotype: major/minor, $\mathrm{n}$

Fibrosis stage: 1-2/3-4 $4^{\mathrm{a}}, \mathrm{n}$
25

$56.5 \pm 8.9$

$16 / 9$

$23.7 \pm 3.7$

$6.01 \pm 0.77$

$63.4 \pm 56.6$

$83.6 \pm 84.9$

$70.8 \pm 104.4$

$14.1 \pm 1.41$

$18.6 \pm 5.6$

$173.7 \pm 27.0$

$49.1 \pm 32.1$

$10.5 \pm 1.9$

$23 / 2$

$21 / 4$

$18 / 3$

8

$60.6 \pm 7.0$

$5 / 3$

$26.3 \pm 8.3$

$6.19 \pm 1.15$

$46.1 \pm 23.2$

$53.5 \pm 31.1$

$42.5 \pm 28.3$

$14.2 \pm 0.99$

$15.6 \pm 6.3$

$181.9 \pm 25.7$

$55.7 \pm 38.0$

$8.6 \pm 2.4$

$3 / 5$

7/1

$3 / 1$

0.28
1
0.53
0.26
0.53
0.51
0.51
0.55
0.40
0.51
0.54
0.52
$0.004^{\mathrm{b}}$
1
0.83

${ }^{\mathrm{a} A v a i l a b l e ~ s a m p l e ~ n u m b e r ~ o n l y . ~}{ }^{\mathrm{b}} \mathrm{P}=0.004$. Data are presented as mean $\pm \mathrm{SD}$. SVR, sustained virological response; TVR, transient virological response; HCV, hepatitis C virus; SVR, sustained virological response; AST, aspartate transaminase; ALT, alanine transaminase; GTP, glutamyl transpeptidase; PEG-IFN, pegylated interferon; RBV, ribavirin; IL28B, interleukin-28B; MICB, MHC class I-related chain B; SD, standard deviation.

determinants for response to treatment is considered a high priority.

MICB is a ligand for the NKG2D activating receptor expressed on NK cells, natural killer T (NKT) cells, cluster of differentiation $8^{+} \mathrm{T}$ cells and $\gamma \delta \mathrm{T}$ cells (36). NKG2D ligand expression is stress-related and upregulated by infected or oncogenic cells leading to cytolysis. $M I C B$ genes exhibit considerable polymorphism among individuals and studies have investigated allelic association with disease (37-39). The $M I C B$ SNP rs3828913 (position -176) is located adjacent to the heat-shock response element and the GC box in the $M I C B$ promoter (40), and plays a role in transcriptional activation of the $M I C B$ gene. Previous studies reported that IFN- $\alpha$ stimulates $M I C B$ expression in DCs, leading to activation of NK cells, which play an important role in host antiviral activity. In addition, in patients with $\mathrm{HCV}$-infection the $M I C B$ induction of DCs is severely impaired and this impairment may play a specific role in HCV infection (22). These observations prompted the investigation of the association between $M I C B$ SNP rs3828913 and treatment outcome of PEG-IFN/RBV therapy in patients with $\mathrm{HCV}$ infection.

In the present study, the $M I C B$ genotype, as well as the $I L 28 B$ major genotype and lower HCV-RNA level, were significantly associated with SVR in HCV patients. Although the predictive power of the $M I C B$ major genotype was not as strong as that of the $I L 28 B$ major genotype (OR, 7.14; 95\% CI, 2.19-23.22), it appeared to be sufficient for clinical use (OR, 4.47; 95\% CI, 1.46-13.70). When limited to HCV serotype 1 patients, the predictive power of the $M I C B$ major genotype for SVR was not significant, but the $M I C B$ minor genotype was useful for prediction of NVR in these patients (OR, 5.8; 95\% CI, 1.5-21.8). As mentioned above, a considerable number of $\mathrm{HCV}$ serotype 1 patients with the $I L 28 B$ major genotype $(\sim 50 \%)$ are resistant to $\mathrm{PEG}-\mathrm{IFN} / \mathrm{RBV}$ therapy (14). Therefore, the predictive power of the $M I C B$ genotype was analyzed for achievement of SVR in HCV serotype 1 patients with the $I L-28$ major genotype. In $\mathrm{HCV}$ serotype 1 patients with the $I L-28$ major genotype, the achievement of SVR by patients with the MICB major genotype was 6.74-fold higher than that of the patients with the $M I C B$ minor genotype (Table VII). Conversely, the $M I C B$ minor genotype appeared to be useful for prediction of NVR in HCV serotype 1 patients with the IL28B major genotype (OR, 5.89; 95\% CI; 1.22-28.5). When limited to HCV serotype 2 patients, the $M I C B$ major genotype is the sole factor associated with SVR.

The combination of the HCV protease inhibitor with PEG-IFN/RBV was recently introduced for anti-HCV therapy and was reported to achieve higher antiviral responses (15). However, the SVR rate of non-responders who previously failed to respond to IFN-based therapy was only $40-50 \%(15,16)$. Therefore, the present data regarding the use of $M I C B$ genotyping for the prediction of response to therapy should contribute to a higher SVR rate in selected treated patients. In the future, the clinical utility of $M I C B$ genotyping should be evaluated as a predictive factor of the efficacy of the $\mathrm{HCV}$ protease inhibitor combined to PEG-IFN/RBV.

In conclusion, the $M I C B$ genotype is a strong predictive factor of virological response to PEG-IFN/RBV therapy in $\mathrm{HCV}$ patients. $M I C B$ genotyping may become part of the 
clinical assessment prior to standard antiviral therapy in individuals chronically infected with $\mathrm{HCV}$.

\section{References}

1. Chayama K, Hayes CN, Ohishi W and Kawakami Y: Treatment of chronic hepatitis $\mathrm{C}$ virus infection in Japan: update on therapy and guidelines. J Gastroenterol 48: 1-12, 2013.

2. Kim MN, Kim BK and Han KH: Hepatocellular carcinoma in patients with chronic hepatitis $\mathrm{C}$ virus infection in the Asia-Pacific region. J Gastroenterol 48: 681-688, 2013.

3. Chuang WL and Yu ML: Host factors determining the efficacy of hepatitis C treatment. J Gastroenterol 48: 22-30, 2013.

4. Minami T, Kishikawa T, Sato M, Tateishi R, Yoshida $H$ and Koike K: Meta-analysis: mortality and serious adverse events of peginterferon plus ribavirin therapy for chronic hepatitis $\mathrm{C}$. J Gastroenterol 48: 254-268, 2013.

5. Yamashita N, Ohho A, Yamasaki A, Kurokawa M, Kotoh K and Kajiwara E: Hepatocarcinogenesis in chronic hepatitis $\mathrm{C}$ patients achieving a sustained virological response to interferon: significance of lifelong periodic cancer screening for improving outcomes. J Gastroenterol 49: 1504-1513, 2014.

6. Nishiguchi S, Enomoto H, Aizawa N, et al: Relevance of the Core 70 and IL-28B polymorphism and response-guided therapy of peginterferon alfa-2a \pm ribavirin for chronic hepatitis $\mathrm{C}$ of Genotype 1b: a multicenter randomized trial, ReGIT-J study. J Gastroenterol 49: 492-501, 2014.

7. Asahina Y, Tsuchiya K, Nishimura T, et al: Genetic variation near interleukin $28 \mathrm{~B}$ and the risk of hepatocellular carcinoma in patients with chronic hepatitis C. J Gastroenterol 49: 1152-1162, 2014.

8. Miyase S, Haraoka K, Ouchida Y, Morishita Y and Fujiyama S: Randomized trial of peginterferon alpha-2a plus ribavirin versus peginterferon alpha-2b plus ribavirin for chronic hepatitis $C$ in Japanese patients. J Gastroenterol 47: 1014-1021, 2012.

9. Enomoto M, Tamori A, Kobayashi S, Iwai S, Morikawa H and Kawada N: Treatment guidelines for HCV genotype 1: mono for low, triple for high, and dual for 'middle'? J Gastroenterol 48: 555-556, 2013

10. Sato M, Kato N, Tateishi R, et al: IL28B minor allele is associated with a younger age of onset of hepatocellular carcinoma in patients with chronic hepatitis $\mathrm{C}$ virus infection. J Gastroenterol 49: 748-754, 2014.

11. Okita K, Izumi N, Matsui O, et al: Peretinoin after curative therapy of hepatitis C-related hepatocellular carcinoma: a randomized double-blind placebo-controlled study. J Gastroenterol: Apr 13 2014 (Epub ahead of print).

12. Izumi N, Asahina $\mathrm{Y}$, Kurosaki M, et al: Inhibition of hepatocellular carcinoma by PegIFN $\alpha-2 a$ in patients with chronic hepatitis C: a nationwide multicenter cooperative study. J Gastroenterol 48: 382-390, 2013.

13. Fried MW, Shiffman ML, Reddy KR, et al: Peginterferon alfa-2a plus ribavirin for chronic hepatitis $\mathrm{C}$ virus infection. $\mathrm{N}$ Engl $\mathrm{J}$ Med 347: 975-982, 2002

14. Kurosaki M, Tanaka Y, Nishida N, et al: Pre-treatment prediction of response to pegylated-interferon plus ribavirin for chronic hepatitis C using genetic polymorphism in IL28B and viral factors. J Hepatol 54: 439-448, 2011.

15. Hézode C, Forestier N, Dusheiko G, et al: Telaprevir and peginterferon with or without ribavirin for chronic HCV infection. N Engl J Med 360: 1839-1850, 2009.

16. Izumi N, Hayashi N, Kumada H, et al: Once-daily simeprevir with peginterferon and ribavirin for treatment-experienced $\mathrm{HCV}$ genotype 1-infected patients in Japan: the CONCERTO-2 and CONCERTO-3 studies. J Gastroenterol 49: 941-953, 2014.

17. Wang X, Liu F, Wei F, Ren $\mathrm{H}$ and Hu H: Efficacy and safety of pegylated interferon plus ribavirin therapy for chronic hepatitis $\mathrm{C}$ genotype 6: a meta-analysis. PLoS One 9: e100128, 2014.

18. Holder KA, Stapleton SN, Gallant ME, Russell RS and Grant MD Hepatitis C virus-infected cells downregulate NKp30 and inhibit ex vivo NK cell functions. J Immunol 191: 3308-3318, 2013.

19. Gonzalez VD, Falconer K, Björkström NK, et al: Expansion of functionally skewed CD56-negative NK cells in chronic hepatitis $\mathrm{C}$ virus infection: correlation with outcome of pegylated IFN-alpha and ribavirin treatment. J Immunol 183: 6612-6618, 2009.
20. Zeromski J, Mozer-Lisewska I, Kaczmarek M, KowalaPiaskowska A and Sikora J: NK cells prevalence, subsets and function in viral hepatitis C. Arch Immunol Ther Exp (Warsz) 59: 449-455, 2011

21. Jinushi M, Takehara $\mathrm{T}$, Tatsumi $\mathrm{T}$, et al: Impairment of natural killer cell and dendritic cell functions by the soluble form of MHC class I-related chain A in advanced human hepatocellular carcinomas. J Hepatol 43: 1013-1020, 2005.

22. Jinushi M, Takehara T, Kanto T, et al: Critical role of MHC class I-related chain A and B expression on IFN-alpha-stimulated dendritic cells in NK cell activation: impairment in chronic hepatitis C virus infection. J Immunol 170: 1249-1256, 2003.

23. Iino S, Ichida F, Sakuma A and Suzuki H: A randomized clinical trial with natural interferon-alpha monotherapy for 24 or 48 weeks on patients with chronic hepatitis $C$ having genotype $1 \mathrm{~b}$ infection in high viral titers. Hepatol Res 24: 338-345, 2002.

24. Enomoto N, Sakuma I, Asahina Y, et al: Mutations in the nonstructural protein $5 \mathrm{~A}$ gene and response to interferon in patients with chronic hepatitis $\mathrm{C}$ virus $1 \mathrm{~b}$ infection. $\mathrm{N}$ Engl J Med 334: 77-81, 1996.

25. Akuta N, Suzuki F, Kawamura Y, et al: Predictors of viral kinetics to peginterferon plus ribavirin combination therapy in Japanese patients infected with hepatitis $C$ virus genotype $1 b$. J Med Virol 79: 1686-1695, 2007

26. Yasui K, Harano Y, Mitsuyoshi H, et al: Steatosis and hepatic expression of genes regulating lipid metabolism in Japanese patients infected with hepatitis C virus. J Gastroenterol 45: 95-104, 2010.

27. Izumi N, Asahina Y and Kurosaki M: Predictors of virological response to a combination therapy with pegylated interferon plus ribavirin including virus and host factors. Hepat Res Treat 2010: 703602, 2010.

28. Tanaka Y, Nishida N, Sugiyama M, et al: Genome-wide association of IL28B with response to pegylated interferon-alpha and ribavirin therapy for chronic hepatitis C. Nat Genet 41: 1105-1109, 2009

29. Ge D, Fellay J, Thompson AJ, et al: Genetic variation in IL28B predicts hepatitis C treatment-induced viral clearance. Nature 461: 399-401, 2009

30. Kobayashi M, Suzuki F, Akuta N, et al: Association of two polymorphisms of the IL28B gene with viral factors and treatment response in 1,518 patients infected with hepatitis $\mathrm{C}$ virus. J Gastroenterol 47: 596-605, 2012.

31. Ahlenstiel G, Booth DR and George J: IL-28B in hepatitis C virus infection: translating pharmacogenomics into clinical practice. J Gastroenterol 45: 903-910, 2010.

32. Ichida F, Tsuji T, Omata M et al: New Inuyama classification; new criteria for histological assessment of chronic hepatitis. Int Hepatol Commun 6: 112-119, 1996.

33. Ochi H, Maekawa T, Abe H, et al: IL-28B predicts response to chronic hepatitis $\mathrm{C}$ therapy - fine-mapping and replication study in Asian populations. J Gen Virol 92: 1071-1081, 2011.

34. Kurosaki M, Sakamoto N, Iwasaki M, et al: Pretreatment prediction of response to peginterferon plus ribavirin therapy in genotype 1 chronic hepatitis $\mathrm{C}$ using data mining analysis. J Gastroenterol 46: 401-409, 2011.

35. Sinn DH, Kim YJ, Lee ST, et al: Association of a single nucleotide polymorphism near the interleukin-28B gene with response to hepatitis C therapy in Asian patients. J Gastroenterol Hepatol 26: 1374-1379, 2011

36. Cox ST, Madrigal JA and Saudemont A: Diversity and characterization of polymorphic 5' promoter haplotypes of MICA and MICB genes. Tissue Antigens 84: 293-303, 2014.

37. Kimura T, Goto K, Yabuki K, et al: Microsatellite polymorphism within the MICB gene among Japanese patients with Behçet's disease. Hum Immunol 59: 500-502, 1998.

38. Rodriguez-Rodero S, Rodrigo L, Fdez-Morera JL, et al: MHC class I chain-related gene B promoter polymorphisms and celiac disease. Hum Immunol 67: 208-214, 2006.

39. González S1, Rodrigo L, López-Vázquez A, et al: Association of MHC class I related gene B (MICB) to celiac disease. Am J Gastroenterol 99: 676-680, 2004.

40. Pan F, Li L, Luo J, Liu X and Tian W: The 5' promoter region of MHC class I chain-related gene B. Tissue Antigens 83: 337-343, 2014. 